\title{
AS TENTATIVAS EXTREMAS DE ANTONIN ARTAUD DE RECOBRAR O NOME SOB A LETRA
}

Serge Bedere

Psicanalista,
membro do
Espace Analytique e
membro fundador
do Point Rencontre,
de Bordeaux.
Tradução: Marie
Dominique
Grandy

RESUMO: Após longo período marcado por uma convicção delirante concernente ao nome - Antonin Artaud teria morrido e Antonin Nalpas teria se apoderado de seu corpo - Artaud recobra o uso de seu nome. Considera-se aqui a retomada, por Artaud, de seu nome e suas articulações com a volta à escrita, a transferência com Gaston Ferdière e o trabalho sobre a letra por meio da tradução do Jabberwocky, de Lewis Carrol.

Palavras-chave: Artaud, escrita, corpo, letra.

ABSTRACT: The extreme tries from Antonin Artaud of recovering the name below the letter. After a long period of time market by the hallucinating concern about the name - Antonin Artaud would have died and Antonin Nalpas would have taken over his body - Artaud recovers the use of his name. It is to be considered the recover, by Artaud, of his name and his articulations with the return to writing, the transference with Gaston Ferdière and the work about letters by the means of translations from Jabberwock, by Lewis Carrol.

Keywords: Artaud, writing, body, letter.

Atonin Artaud - apesar de certas pessoas considerarem
submetido lá e o fato de ter sido julgado psicótico - - não
voltou para Paris curado de sua esquizofrenia.
Além da conferência do Vieux Colombier, a seguinte
anedota relatada em um bate-papo por Georges-Emmanuel
Clancier dá bem a idéia de que sua pacificação era apenas
relativa, podendo ceder sem maiores esforços. 
"Eu era um amigo de adolescência de Paule Pastier-Thévenin.

Nos reencontramos em Paris.

Ela propôs que eu viesse jantar; nos encontramos no “Aux deux Magots”, com René Blain e Artaud, que eu não conhecia.

De fato, eu já havia encontrado Elie Lascaux, o pintor, o qual me havia apresentado Raymond Queneau, um amigo próximo; ele me havia dito que Artaud também o conhecia.

Eis-me então frente a ele, enquanto Paule conversa com Blain, sem se preocupar conosco, e eu 'estupidamente', lhe digo: 'Temos um amigo comum, Elie Lascaux'.

Então, ele me lança o mais negro dos olhares e diz com uma voz cavernosa:

‘Amigo...? Amigo, não, Elie Lescaux, I...N...I...M...I...G...O!', e não me dirige mais a palavra.

Depois, fomos jantar no 'Au Vieux Paris'; Paule continuou a conversar com Blain, e durante toda a refeição, Artaud, sentado a minha frente, não disse nada. Observei que uma de suas mãos estava debaixo da mesa e ouvi ruídos regulares sem parar; na verdade, ele passara o jantar inteiro dando facadas, por baixo, na madeira da mesa...!

Em seguida, fomos tomar alguma coisa no 'Bar Vert'; Paule e Blain encontraram um monte de amigos e Artaud e eu fomos os únicos silenciosos!! Fiquei aterrorizado a noite toda."1

Mas ao menos ele voltou com vida, e novamente sujeito de seu nome e de sua obra (tudo leva a crer que não teria sido forçosamente este o caso se não tivesse sido transferido de Ville-Evrard para Rodez, em zona livre: poderia ter sido mais um entre os milhares de doentes mentais mortos de fome em asilos quando a França se encontrava sob ocupação alemã).

O episódio crepuscular que se seguiu à sua internação forçada no Havre, após sua repatriação da Irlanda, em 1937, resultado da "restituição" da bengala de St. Patrick, foi efetivamente marcado por uma convicção delirante concernente ao nome. Antonin reivindicava o fato de que se devia levar em consideração a morte de Antonin Artaud e o fato de que Antonin Nalpas apoderara-se do corpo deste último em agosto de 1939 — reivindicação esta que durou vários anos e que o levou a querer processar a administração dos hospitais para obter deles o reconhecimento deste "novo" nome.

Foi em Rodez, no mês de setembro de 1943, em circunstâncias peculiares, que Antonin recobrou o uso do nome Artaud e que dele tornou-se novamente sujeito, para nunca mais deixá-lo, até seus últimos dias, fosse qual fosse seu humor ou estado de ânimo.

${ }^{1}$ Georges-Emmanuel Clancier, conversa particular, Villars sur Olon (Suíça), 29 de agosto de 2003. 
Este fato clínico parece-nos em si muito interessante, e portanto pensamos que merece que retomemos aqui, passo a passo, suas articulações: está completamente ligado à volta à escrita, à transferência complexa com Gaston Ferdière, e ao trabalho sobre a letra através da tradução do Jabberwocky de Lewis Carroll em setembro de 1943.

Devemos antes, porém, esboçar um quadro que nos permita ter uma visão de conjunto, e retomar o contexto geral dos acontecimentos anteriores, passando pelo fracasso da poesia, a insuficiência do teatro, o que não deixará de nos lembrar a paisagem de nossa viagem ao país de Wolfson.

Segundo a fórmula de Derrida, "Artaud nos ensina esta unidade anterior à dissociação" (DERRIDA, 1967, p.260), o que caracteriza e singulariza seu percurso.

Tomaremos por base alguns de seus textos, ${ }^{2}$ assim como os trabalhos de Michel Demangeat, La scène, le sacré, la survie [A cena, o sagrado, a sobrevida] (1995) e Mort et Transfiguration: origines du nouveau style d'Artaud à partir des lettres de Rodez" [Morte e transfiguração: origens do novo estilo de Artaud a partir das cartas de Rodez] (1995).

Nossa pista de trabalho está centrada em torno da tentativa de Artaud para "refazer o caminho inversamente", de alguma maneira, como experiência para criar uma espécie de escrita do corpo, "um sistema de signos onde não mais comanda a instituição da voz" (DEMANGEAT, 1995, p.287).

"O desmoronamento central da alma" pressentido por Artaud desde sua entrada na carreira literária tem a mesma natureza, a mesma origem estrutural que o "fim do mundo" descoberto por Freud no limiar do grande delírio cósmico do Presidente Schreber.

"Esta ameaça está associada nas cartas para Jacques Rivière a idéias de perseguição", observa Michel Demangeat, que durante muito tempo freqüentou os textos de Artaud antes de sublinhar que aí onde Schreber falava em "assassinato de alma", Artaud evoca, para designar esse verdadeiro sentimento de se ser a presa de um trabalho incessante de solapamento, "este algo furtivo que me rouba as palavras que encontrei" ${ }^{3}$, lembrando que Jacques Rivière achou a este respeito "o termo definitivo de "furtos interiores".".

Parece-me que vemos em Artaud uma dupla tentativa desesperada: a de reencontrar o corpo perdido dentro e através das palavras; e a de tentar reencontrar

\footnotetext{
2 “La parole soufflée" [A palavra soprada], op.cit., p.253-292; “Le Théâtre de la Cruauté et la clôture de la Représentation" [O teatro da crueldade e o fechamento da representação], op.cit., p.341-368.

${ }^{3}$ Trata-se de uma fórmula de Artaud, Oeuvres complètes, p.25-26.

${ }^{4}$ Michel Demangeat, "Mort et Transfiguration: origine du nouveau style d'Artaud à partir des lettres de Rodez", p.2.
} 
as próprias palavras ("Dez anos que a linguagem se foi” escrevia ele em janeiro de 1948, antes de evocar "algo que destrói meu pensamento (...) um algo furtivo que me rouba as palavras que encontrei”), e reinventar uma linguagem "descontaminada” da presença do Outro e das marcas de sua voz, o que só poderá ser efetivado dirigindo-se para o lado da escrita teatral, após a constatação do fracasso da escrita poética (voltaremos a este ponto); e mais: com a condição de nela reintroduzir até mesmo o grito.

Derrida, cuja paixão por Artaud transparecia com a mesma vivacidade por ocasião da retomada da conferência do Moma em Paris no outono de 2003 — que também terá sido a última — propôs que se resumisse assim o percurso da escrita de Artaud em Position de la chair [Posição da carne]:

"refaço a cada uma das vibrações de minha língua todos os caminhos do pensamento em minha carne. (..) Desde que tenho relação com meu corpo, ou seja, desde meu nascimento, não sou mais meu corpo. Então tenho um corpo, não o sou, logo, não o tenho.” (DERRIDA, 2003, p.268-269)

Artaud, vendo-se então na posição de mártir da língua, pelo fato de "furtos interiores" tornarem impossível para ele tentar aproximar-se de si mesmo.

Vejamos alguns trechos do texto de Artaud:

"E que fizeste de meu corpo, Deus?"5 (a figura de Deus vem ocupar aqui o lugar do Outro)

"Meu corpo refez-se apesar de tudo

contra

e através de mil assaltos do mal

e do ódio

que o deterioravam a cada vez

e me deixavam morto"6

"Fui por demais supliciado

(...)

Trabalhei demais para ser puro e forte

(...)

Busquei demais ter um corpo próprio."7

"O corpo é o corpo

ele é só

não precisa de órgãos

\footnotetext{
${ }^{5}$ Artaud, Oeuvres Complètes, p.108

${ }^{6}$ Idem, p.109.

${ }^{7}$ Idem, p. 135.
} 
o corpo não é jamais um organismo

os organismos são os inimigos do corpo

as coisas que fazemos acontecem sozinhas sem auxílio de um órgão

todo órgão é um parasita

ele cobre uma fração parasitária

destinado a fazer viver um ser que não deveria estar aí"8

“eu estava vivo e estava aí desde sempre

Comerei?

Não,

Mas quando tinha fome recuava com meu corpo,

e não me comerei eu mesmo

Mas isso tudo se descompôs

Uma operação estranha ocorria...

Eu dormia?

Não, não dormia,

É preciso ser casto para saber não comer.

Abrir a boca é oferecer-se aos miasmas.

Logo, nada de boca.

Nada de boca,

Nada de língua,

Nada de dentes,

Nada de laringe,

Nada de esôfago,

Nada de estômago,

Nada de ventre,

Nada de ânus.

Reconstruirei o homem que sou"9

“Sou eu

que

me

terei refeito eu mesmo

inteiramente..

por mim

que sou um corpo

que não tenho em mim regiões"10

\footnotetext{
${ }^{8}$ Idem, p.101.

${ }^{9}$ Idem, novembro de 1947, in Oeuvres Complètes, p.102.

${ }^{10}$ Ibidem.
}

Ágora (Rio de Janeiro) v. X n. 1 jan/jun 2007 9-34 
A tarefa, convenhamos, é sobre-humana; a obra a ser refeita incessantemente, mal esboçada, já desmorona.

Esses escritos datam de 1947, depois da saída de Rodez, logo, alguns meses antes de sua morte em março de 1948. Não há como se enganar: trata-se aí da obra de toda uma vida.

Vinte quatro anos antes, Artaud escrevia o seguinte:

"eu ainda trabalhava durante um mês escrevendo um poema verbalmente, e gramaticalmente, com bom êxito. Depois, deixei de lado. A questão para mim não era saber o que conseguiria insinuar-se nos quadros da linguagem escrita, mas sim dentro da trama de minha alma em vida". ${ }^{11}$

As diversas tentativas de escrita fazem de Antonin uma presa desta questão aterrorizante e, esperançoso, ele se volta então para o teatro.

"O encaixe das imagens e dos movimentos desembocará, por conivências entre objetos, silêncios, gritos e ritmos sobre a criação de uma verdadeira linguagem física à base de signos, e não mais de palavras."12

Ele faz desta forma a confissão daquilo que constitui o centro de sua tentativa: refazer o caminho inversamente, voltar às primeiras condições da instalação da língua, ao encontro da mímica, à expressão do corpo e do rosto, a esses modos primordiais do encontro com o Outro e com aquela (aquele) que ocupa seu lugar na aurora dos tempos do sujeito.

Mas retornar fixando o movimento, diminuindo o ritmo, o fraseado, livrando-o das sobras de singularidade, de humanidade, de gozo indubitável.

Tentando contornar a dificuldade pelo viés do recurso a um universal suposto, o que vemos claramente exposto, particularmente, em 1931, no escrito "Sur le théâtre balinais" [Sobre o teatro balinês], o qual, diz-ele, "remete o teatro ao seu plano de criação autônoma e pura, sob o ângulo da alucinação e do medo" (ARTAUD, 1964, p.81).

A leitura deste texto é mais esclarecedora ainda sobre a natureza da busca de Artaud: “Tudo neles é regulado assim, impessoal; nenhum jogo de músculos, nenhuma virada de olho que não pareça pertencer a uma espécie de matemática refletida que tudo arrasta e pela qual tudo passa” (1964, p.89). Através dessa “despersonalização sistemática” (idem) trata-se de considerar "seres mecanizados, aos quais nem suas alegrias nem suas dores parecem pertencer propriamente,

${ }^{11}$ Citado por Derrida, p.281.

12 Artaud, Oeuvres Complètes IV, p.149. 
mas obedecer a certos ritos sentidos e como que ditados por inteligências superiores" (idem) e isto se estende além dos corpos das posturas e das mímicas: "além disso há o ritmo largo, fragmentado da música, uma música extremamente pontuada tateante frágil, onde tem-se a impressão de esmagar os metais mais preciosos" (idem), ou seja, de chegar à "uma expressão de desumanidade, de divino, de revelação milagrosa" (p.90).

"Neste teatro, menciona ainda Artaud, toda criação vem do palco, encontra sua tradução e suas próprias origens em um impulso psíquico secreto que é a palavra de antes dos vocábulos" (idem, p.91).

Ou seja, trata-se de "des-iniciar" a linguagem da presença do Outro, tentar recomeçar do zero para voltar a um estado primeiro, reencontrar "um estado de antes da linguagem e que pode escolher sua linguagem: música, gestos, movimentos, palavras" (idem, p.94). Trata-se de achar "esse silêncio triturado de pensamentos que existe entre os membros de uma frase escrita" (idem, p.95).

Tentar percorrer ao inverso o curso das coisas e da história e descontruindo/ reconstruindo o que fez a matriz da relação do sujeito à língua, precisamente naquilo que aprendemos a reconhecer como sendo o mais fundamental na amarração ao Outro, por intermédio da dialética do reconhecimento e da função de espelho do rosto da mãe. ${ }^{13}$

Nesta busca em que "o espírito dos mais antigos hieróglifos presidirá a criação dessa linguagem teatral pura" (DERRIDA, 2003, p.73; p.107), como observa Derrida, "não só a voz não dará mais as ordens, mas ela deverá deixar-se ritmar pela lei dessa escrita teatral" (idem, p.287).

Trata-se de um sistema de escrita não fonética, uma forma de escrita do grito, um sistema codificado de onomatopéias, de gestos e de expressão, "uma verdadeira 'pasigrafia' teatral portando além das línguas empíricas” (idem), retomado posteriormente nas cartas de Rodez com uma preocupação de ser escrita universal, uma língua "que não seria o francês e na qual cada todo mundo poderia ler, não importando sua nacionalidade." ${ }^{14}$

Eis as precisões que o próprio Artaud nos dá:

“As dez mil e uma expressões do rosto tomadas em estado de máscaras poderão ser etiquetadas e catalogadas, em vistas de participar diretamente e simbolicamente desta linguagem concreta”. ${ }^{15}$

\footnotetext{
${ }^{13}$ Ver sobre isto as intervenções de Michel Demangeat e Françoise Efel no Colóquio sobre as Psicoses, em Bruxelas, no dia 8 de novembro de 2002, no prelo.

${ }^{14}$ Artaud, carta para Henri Parisot.

15 Artaud, "Le Théâtre et son double”, p.145.
} 
E sua concepção do papel e da função dos atores:

"Os atores com seus figurinos compõem verdadeiros hieróglifos que vivem e se movem. E estes hieróglifos de três dimensões são por sua vez bordados com certo número de gestos, de sinais misteriosos, que correspondem a não sabemos que realidade fabulosa e obscura que nós outros, pessoas do Ocidente, reprimimos definitivamente."16

Eis como Derrida imagina o procedimento de Artaud, propondo uma reconstrução escrita na primeira pessoa, na suplência daquela que Artaud não pode sustentar a não ser por sua própria obra:

"Não é a seu favor, mas entre duas escritas que a diferença furtiva pudera insinuarse, localizando minha vida 'fora de obra' e fazendo de sua origem, de minha carne, o exergo inebriante sem fôlego de meu discurso. Era preciso através da escrita feita carne, pelo hieróglifo teatral, destruir o duplo, apagar a escrita apócrifa que, roubando-me o ser como vida, mantinha-me à distância da força escondida, agora o discurso pode juntar-se a seu nascimento em uma perfeita e permanente presença a si." (DERRIDA, 2003, p.289)

Trata-se de tentar recobrar "um saber presente do próprio passado de nossa palavra" (idem), tentar remontar o mecanismo do efeito "pós-golpe" próprio do ato de enunciação. Escreve o próprio Artaud:

"Pode acontecer que tal maneirismo, tal compulsão excessiva, com seu alfabeto rolante, com seus gritos de pedras que se fendem, com seus ruídos de ramos, seus ruídos de cortes e de rolamento de madeira, componha no ar, no espaço, uma espécie de sussurro material e animado. E após um instante a identificação mágica está feita: sabemos que somos nós que falamos." (1964, p.103)

E obrigam-no a "fazer o caminho inversamente" a fim de tentar elaborar uma arqueologia da relação à língua que lhe deixe maiores chances.

É uma derradeira tentativa, de poder reencontrar um hábitat dentro da língua, e, para tanto, voltar aos gestos.

"Desconstituindo o diáfano, desnudamos a carne da palavra, sua sonoridade, sua entonação, sua intensidade, o grito que a articulação da língua e da lógica ainda

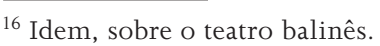


não esfriou totalmente, o que resta de gesto oprimido em toda palavra”, sublinha Derrida (2003, p.352).

E assim se faz uso da onomatopéia, em um movimento que nos leva de volta “à beira do momento em que a palavra ainda não era nascida" (idem);

"trata-se então menos de construir uma cena muda do que uma cena cujo clamor ainda não foi apaziguado na palavra.

A palavra é o cadáver da palavra psíquica, e é preciso reencontrar, junto com a linguagem da própria vida, 'a palavra de antes dos vocábulos' (idem).

Artaud explica seu objetivo: "Acrescento à linguagem falada outra linguagem, e tento devolver sua velha eficácia mágica, sua eficácia subjugante, integral, à linguagem da palavra de cujas misteriosas possibilidades esquecemos." ${ }^{7}$

“Para além do vazio, 'do mundo sem objeto', o que é feito da Coisa, ‘aquilo que do real sofre do significante'?”...pergunta Michel Demangeat no final de seu artigo.

Acho que posso arriscar afirmar, junto com ele e depois do que acabamos de rever dos escritos de Artaud, que nesta tentativa trata-se de pôr mal à supremacia da palavra carregada pela voz, de recobrar a matéria da língua, a brutalidade de um real que, em suma, não deveria sofrer pelo significante.

É nisto que consiste a aposta do Teatro da Crueldade, assim chamado pelo fato de que ele "não é o símbolo de um vazio ausente, de uma pavorosa incapacidade de se realizar em sua vida de homem, mas a afirmação de uma terrível e inevitável necessidade".18

A noção de hieróglifo está no centro do Primeiro Manifesto, em 1932:

“tendo se conscientizado desta linguagem no espaço, linguagem de sons, de gritos, de luz, de onomatopéias, o teatro tem a obrigação de organizá-la fazendo dos personagens e objetos verdadeiros hieróglifos, usando seu simbolismo e suas correspondências em relação a todos os órgãos e em todos os planos." ${ }^{19}$

Trata-se de uma verdadeira arqueologia, que por meio de um sistema de signos, tenta criar novamente o corpo perdido dentro das palavras.

Dar novamente corpo à letra. Nem que seja necessário reescrever a história do aparecimento da própria língua.

\footnotetext{
${ }^{17}$ Artaud, Oeuvres Complètes, p.133.

${ }^{18}$ Artaud, citado por Derrida. Op.cit., nota de final de página 256.

${ }^{19}$ Artaud, "Le théâtre et son double", p.138.
} 
O que só é possível fazer por intermédio de uma escrita não fonética, tentando libertar, limpar, o ato de palavra da voz, desta marca por meio da qual o Outro deixou o rastro de sua presença, numa tentativa que se faz prima daquela da tradução simultânea à qual recorre Wolfson.

Aqui, porém, é o caso, de alguma maneira, de desconstruir as condições de possibilidade do encontro, do encontro com toda a figura representando o Outro, de toda figura marcada de humanidade, de todo rosto suscetível de sorrir.

E, adiantando-nos um pouco mais na lógica, é o inédito através do teatro que se deve fazer surgir, e deste modo, a repetição da representação vai ser problema.

É o aparecimento que é preciso acuar. Nem que se remonte ao próprio grito. Com este rastro que ficará da conferência do Vieux Colombier...

Aliás, é bem o que encontramos sob a caneta de Artaud:

"não se tratará de suprimir a palavra articulada, mas de dar de novo aos termos aproximadamente a importância que têm nos sonhos (...), de desmultiplicar por tipos de gestos e atitudes reflexo, constituídos pelo monte de todos os gestos impulsivos, todas as atitudes falhas, todos os lapsos do espírito e da língua, pelos quais se manifesta aquilo que poderíamos chamar as impotências da palavra". ${ }^{20}$

Este "espetáculo integral", ${ }^{21}$ que exige que acabemos de passagem com a distinção entre palco e platéia, "é um espetáculo cifrado do começo ao fim, como uma linguagem". ${ }^{22}$

Mas o empreendimento tem por finalidade "romper com o sentido usual da linguagem" (carta para Jean Paulhan, de 13 de setembro de 1932, ARTAUD, 1964, p.158); "a linguagem das palavras deve ceder seu lugar à linguagem por signos cujo aspecto objetivo é o que nos afeta imediatamente melhor" (carta para Benjamin Crémieux, de 15 de setembro de 1931, idem, p.170).

Artaud é extraordinariamente lúcido e preciso:

"trata-se de substituir a linguagem articulada por uma linguagem diferente por natureza, cujas possibilidades expressivas serão equivalentes à linguagem das palavras, mas cuja fonte será tomada em um ponto ainda mais fundo e recuado do pensamento". (carta para Jean Paulhan, de 28 de setembro de 1932, idem, p.158)

\footnotetext{
${ }^{20}$ Idem, p.145-146.

${ }^{21}$ Idem, p.152.

22 Ibidem.
} 
O papel do gesto é evidenciado da maneira mais clara possível: "ele refaz poeticamente o trajeto que desembocou na criação da linguagem" (idem, p.171).

Trata-se verdadeiramente de uma tentativa de remontar o curso das coisas, vista como tal. E de remontar até, e inclusive, as condições mesmas da enunciação.

Neste teatro, ainda podemos ler sob os dedos de Artaud: "uma palavra escrita tem tanto valor quanto a mesma palavra pronunciada" (carta para Jean Paulhan, de 28 de maio de 1933, idem, p.183). O que significa fazer voltar sobretudo "o que toca à enunciação particular de uma palavra, à vibração que ela pode espalhar no espaço que habitualmente escapa, assim como aquilo que por isto ela é capaz de acrescentar ao pensamento" (idem).

Ao fazer com que as coisas funcionem novamente a partir do sopro humano, a propósito do qual Artaud lembra de passagem que ele se apóia sobre as numerosas combinações das "ternárias cabalísticas" (carta para Jean Paulhan, de 28 de setembro de 1932, idem, p.174), a questão é reinventar "uma música da palavra que fale diretamente ao inconsciente" (carta para Jean Paulhan, de 28 de maio de 1933, idem, p.184). Nada menos.

Graças à interpretação do ator, este "atleta do coração", 23 eis que "a linguagem da literatura se recompõe, torna-se viva" (idem, p.186).

Mas será preciso para tanto voltar até o grito, aquele mesmo, urrado na aurora dos tempos do sujeito pela criança.

Sobre oito páginas do Théâtre de Séraphin (ARTAUD,1936/1964, p.223-231), um ensaio redigido em 1936, podemos contar 23 vezes a palavra grito, observa Michel Demangeat antes de citar Artaud: "isto quer dizer que quando interpreto, meu grito cessou de rodar sobre si, mas que ele desperta seu duplo das fontes nas muralhas do subterrâneo", e antes de afirmar que em seguida "de 1943 a 1946, a penetração do corpo e de seu grito na escrita é efetuada por inscrição direta torcendo o texto como uma boca que cospe palavras inventadas":

"Soquem meu corpo até que ele entregue a alma, e se torne opaco, espesso, 'surbondé”

Yo mi bi

Do eghi mito

Eghi vinto tchevo

Quer dizer se revolte e arda em um braseiro mais potente (tônus de vida)

As faíscas retornam

\footnotetext{
${ }^{23}$ Artaud, "Um atletismo afetivo" [Um athlétisme affectif], in "Le Théâtre et son double", p.199.
} 
Tudo derrete

Nada."

"O teatro é um transbordar passional,

uma aterradora transferência de forças,

do corpo,

ao corpo.

Esta transferência não pode se reproduzir duas vezes."

escreve Artaud em 1946. ${ }^{24}$

Introduzindo assim o drama do ponto de entrave, para que o teatro conserve realmente sua eficácia, seria necessário um teatro livre da questão da repetição através das representações, um teatro de performance única, ou seja, um teatro nos limites do teatro.

Se o problema for falência, escreve ainda Michel Demangeat, ela, no entanto, autoriza a invenção de uma nova linguagem poética, antes de concluir este estudo de 1994 sobre uma fórmula de grande beleza:

"Cavador de poços do originário, Artaud faz com que sua escrita gravite em volta de um grito de angústia” (DEMANGEAT, 1995, p.122).

Michel Demangeat sublinha as viradas observáveis na trajetória literária de Artaud em função de períodos. Vamos acompanhar seu trabalho:

De 1920 a 1925: a cena parece ser o lugar privilegiado no qual Artaud evolui.

De 1935 a 1937: ele se apóia em um grande impulso para o sagrado (sobretudo por sua viagem ao México).

Em 1937, trata-se de sobrevida pela escrita, à beira do desmoronamento mental: “Na proa da invenção literária, Les Nouvelles Révélations de l’Être [As novas revelações do ser] constroem aos trancos um texto que domina o caos onde irá se perder adiante." 25

É o ano do desabamento, por ocasião da viagem místico-delirante misteriosa para a Irlanda, quando Artaud resolve devolver a seus proprietários a suposta Bengala de St. Patrick; o início dos anos negros, que serão nove.

Após ter sido preso em Dublin e ter sido forçado a voltar para a França, Artaud é internado no Havre, em seguida em Ville Evrard e depois na Maison Blanche.

\footnotetext{
${ }^{24}$ Citado por Derrida, p.367.

${ }^{25}$ Michel Demangeat, "Mort et Transfiguration, origine du nouveau style d'Artaud à partir des lettres de Rodez" [Morte e transfiguração, origem do novo estilo de Artaud a partir das cartas de Rodez], no prelo, in Eidolon, p.3-4.
} 
A estadia em Rodez durou de 1943 a 1946. Foi então que, progressivamente, Artaud vai reaparecer ao mesmo tempo enquanto sujeito e como autor. Michel Demangeat nos participa do clima de acolhida particular que lhe foi reservado pelo Dr. Ferdière, o qual, pelo fato de pertencer aos meios literários, reconhece de imediato em Artaud o homem de letras e o autor.

Um ressurgimento sob transferência.

Junto com ele, retomaremos passo a passo as etapas deste ressurgimento a respeito do qual é importante reconhecer que se deu "sob transferência": "Caro Doutor e Amigo", é esta de fato a introdução dos escritos dirigidos por Antonin Artaud a Gaston Ferdière. Ao longo de toda esta comovente correspondência, Artaud insiste em se apoiar sobre o desejo deste médico que o convidou a vir passar uma temporada em seu estabelecimento, e jamais deixou de considerá-lo um homem de letras: "Sei da preocupação que o senhor tem com meu caso e minha situação, e vejo perfeitamente que meu comportamento vos causa parte de uma afeição e de uma amizade que são uma das coisas mais raras que jamais senti em toda minha existência", escreve-lhe Artaud em 11 de fevereiro de 44 (ARTAUD, 1977, p.183); e ele continua, no dia 2 de abril: "Há um ano, o senhor me salvou", mas sempre mantendo em relação a ele uma atitude investigadora: "porém ficou no fundo de vosso inconsciente algo que jamais admitiu integralmente minha atitude moral" (idem, p.92).

Transplante de transferência, dizia Gisela Pankow. Parece que isto funcionou...

Mesmo que o tratamento tenha sido penoso (restrição de saídas, eletrochoques que Antonin tentava negociar) nunca Ferdière será visto sob a máscara do perseguidor. Ele será o destinatário dos primeiros desenhos de Artaud, a testemunha de sua volta à escrita e à "vida civil".

Vemos aparecer então, pela primeira vez, o esboço das "glossolalias":

“eu vos espero

Kartoum Antekpta

Karatoum Ksamdartka

Ande Tyana

Com tamanha impaciência, faz tanto tempo".

podemos ler em uma das cartas de Rodez que na época Artaud assinava "Antonin Nalpas”. E após esta recuperação sobre a qual voltaremos com mais detalhes, entre 1946 e 1948, ele foi transferido com a concordância de Ferdière ${ }^{26}$ e de seus

\footnotetext{
${ }^{26}$ Isto não será devidamente compreendido por todos, pois que um processo foi feito contra Ferdière por ter praticado eletrochoques em Artaud, correndo o risco de destruir sua genialidade; um processo do qual acabou sendo declarado inocente, mas que o feriu
} 
mais fiéis amigos para uma casa de saúde da região parisiense, em Evry. Estes últimos organizaram, aliás, uma manifestação em Paris (noite de 7 de junho de 1946 no Teatro Sarah Bernhard, com o patrocínio entre outros de Marthe Robert, Jean Dubuffet, e a participação de vários artistas como Madeleine Renaud, Jean-Louis Barrault, Maria Casarès, Jean Villar, etc.) para angariar fundos para sua instalação; ele pôde a partir de então evoluir livremente, retomar contato com seus amigos e organizar com eles a publicação de suas obras completas, cujo preâmbulo ele mesmo redigiu. Artaud morreu no dia 4 de março.

Poderíamos chamar esses últimos anos de “anos Thévenin”, em virtude da grande atenção e dos cuidados que Paule Thévenin dedicou a Artaud, interrompendo sua formação de psiquiatra para estar a seu inteiro dispor (e depois, para se dedicar à publicação de sua obra), e abrindo para ele quase diariamente a porta de sua própria casa.

O que é absolutamente apaixonante, no trabalho apresentado no presente artigo, é o fato de podermos acompanhar, com o auxílio dessas etapas, as oscilações de Artaud, passando de uma forma de escrita para outra, hesitando entre várias formas de assinatura, debatendo-se no estabelecimento de uma distância em relação à sua mãe, com a possibilidade de ocupar de novo um lugar no mundo das letras, de refazer o funcionamento da suplência de seu estatuto de autor...

Buscando apoiar-se na declinação da problemática do reconhecimento em diversos registros:

Aquele de sua história, com o enigma de um pai capitão quase sempre ausente e odiado, a respeito de quem escreve: "vivi até os 27 anos com o ódio a meu pai, meu pai particular. Até o dia em que assisti à sua morte”. ${ }^{27}$ E a maneira ambivalente segundo a qual ele se situa em relação à mãe, da qual se separa de forma muito categórica várias vezes, quando de fato usa seu nome para assinar outras tantas, antes de conseguir restabelecer uma espécie de relação trinitária entre ele enquanto sujeito, sua obra e sua mãe, em uma escrita que joga sobre a própria letra. Vejamos um exemplo disto:

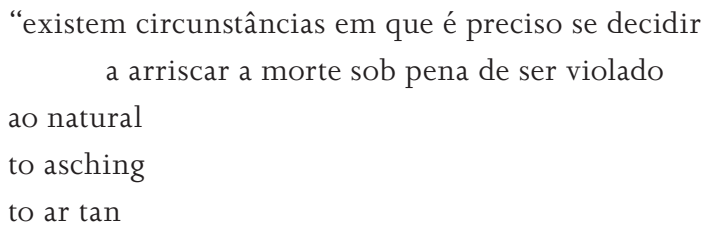

\footnotetext{
bastante. Esta cabala vai persegui-lo durante muito tempo, reaparecendo às vezes com tanta força que ele acabou processando seus detratores e ganhou um processo por difamação em 1970 (DANCHIN e ROUMIEUX, op.cit., p.162).

${ }^{27}$ Citado por Michel Demangeat, em artigo a ser publicado, p.8.
} 
gazura
te gazura
ta hetra”

em que os fonemas do nome Artaud (AR TO, TO AR) são introduzidos. Observemos que aqui o movimento é praticamente o inverso daquele que temos em Joyce; trata-se de tentar agüentar através de invenções de neologismos, para forjar de alguma maneira algo novo, enquanto que em Joyce o que vemos é mais um trabalho de desmontagem, de maltratar a linguagem.

Em termos de estrutura, as coisas também são diferentes: esquizofrenia de Artaud, psicose não descompensada em Joyce. Um tenta se reconstruir, o outro prevenir um desmoronamento possível.

Aquele do meio em que evolui, com um reconhecimento particular enquanto sujeito que sofre, mas também enquanto autor, do qual se beneficia no universo hospitalar de Rodez, o da possibilidade de se manter inscrito ou de se inscrever segundo novas modalidades na comunidade das pessoas letradas: a publicação de textos no estilo de "Kabtar Enis — Kathar esti", a de "Van Gohg suicidado da sociedade", o fato de se interessar pela edição de suas obras completas, cujo prefácio ele mesmo redige...

É extremamente interessante voltarmos, passo a passo, sobre as diversas etapas da retomada da escrita, cujo contexto situamos "sob transferência", depois de seis anos de total interrupção.

“Antonin ARTAUD ${ }^{28}$ era de fato um escritor, um homem de teatro e um ator famoso (...)

Antonin Artaud faleceu sob pesar e dor em Ville-Evrard no mês de agosto de 1939 e seu cadáver foi retirado de Ville-Evrard durante uma noite em claro como aquelas a que se refere Dostoievsky.

Assumi sua 'seqüência' e me acrescentei a ele alma por alma e corpo por corpo em um corpo que se formou concretamente e realmente, mas por magia no lugar do seu..."

podemos ler na carta de 12 de fevereiro de 1943, com a assinatura de Antonin NALPAS (ARTAUD, 1977, p.28-29).

Observamos que esta retomada da escrita é tecida de novo no cruzamento do encontro com textos literários que circulam entre ele e Ferdière, entre ele e o exterior, sob o olhar complacente de Ferdière: o Hino aos Demônios de Ronsard

\footnotetext{
${ }^{28}$ Para garantir maior visibilidade, neste trecho em que os nomes patronímicos estão em jogo, eles serão escritos em maiúsculas.
} 
que, ao que parece, Gaston Ferdière faz chegar a suas mãos (carta de 29 de março de 43, idem, p.29-34); (carta de 13 de agosto de 43, idem, p.53-58), as obras de mestre Eckart que Artaud faz passar a Ferdière (carta de 20 de julho de 1946, idem, 47-53), tradução do texto de Lewis Caroll Alice through the looking-glass (carta de 17 a 25 de setembro de 43, idem, 63-67).

Depois de terem trocado entre eles o texto de Ronsard, e das queixas relativas aos eletrochoques, mesmo reconhecendo sua ação benéfica (carta de 25 de junho de 43, idem, p.40), a genealogia volta a ser mencionada em uma carta:

"Eufrásia Artaud, com quem o senhor discutiu as condições de minha estadia em Rodez, era a mãe de Antonin Artaud, mas como o senhor, ela esqueceu a realidade material e objetiva inegável dos acontecimentos fabulosos dos quais vos falo e que ela viveu como o senhor e ela não pode acreditar que eu não seja seu filho.

No entanto, Dr. Ferdière, tenho outra família composta por um pai que se chama Joseph, uma mãe que se chama Marie e cujo sobrenome é NALPAS. Tenho ainda uma irmã cujo nome é Germaine NALPAS.” (carta de 12 de julho de 1943, idem, p.45)

Depois de ter evocado o texto de mestre Eckart, ele mais uma vez retorna à questão do nome:

"Pouco tempo depois de minha chegada aqui o senhor encontrou um Inspetor dos Asilos que lhe falou de mim e vos disse que havia feito um inquérito para elucidar a questão espinhosa de meu estado civil, e que este inquérito havia demonstrado que eu era mesmo Antonin ARTAUD e que minha pretensão de reivindicar o nome de NALPAS era falsa. Este inspetor mentiu porque ela achou que pelo contrário minha família era composta por meu pai Joseph e minha mãe Marie e minha irmã Germaine NALPAS e que me procuravam." (carta de 20 de julho de 1943, idem, p.52).

Após nova evocação do poema de Ronsard, ele continua articulando as coisas assim:

"deixe-me lembrar-lhe Sr. Ferdière que Antonin ARTAUD era o criador de uma dramaturgia que ela não somente expôs em múltiplos escritos mas que ele também materializou no palco durante as encenações de quatro peças que são:

Os Mistérios do Amor, de R.Vitrac

O sonho, de Strinberg

Partilha de Meio dia, de Paul Claudel

Victor ou as crianças no poder, de R.Vitrac e os Cenci que ele mesmo havia compostos segundo Sheylley e Stendhal (...) 
Só lhe resta agora ver um sintoma mórbido condenável e curável no fato que eu pretenda ser Antonin NALPAS e não Antonin ARTAUD. E podem então me reprovar por um fenômeno de desdobramento de personalidade que não se encontra de modo algum em minha consciência pois minha presença na terra é função de um Milagre que se produziu em agosto de 1939 mas que não posso provar já que seria preciso que por magia o senhor fosse transportado para o passado e que o Sr. pudesse ver com seus própriosolhos tudo o que aconteceu naquele momento." (carta de 13 de agosto de 1943, idem, p.53-56)

Foi um mês depois, quando estava começando a trabalhar sobre a tradução do texto de Carroll, ou seja, quando ele se atrelou a uma forma de trabalho sobre a letra - e isto duplamente, pois a parte do texto à qual ele se refere é aquela de Humpty e Dumpty que encena o Mestre das palavras - , que recobrou o uso de seu nome ARTAUD, o qual nunca mais abandonaria:

"Como lhe disse antes de ontem, sofri estes últimos tempos um terrível, porém salutar, abalo; e agora que já passou sinto estar recobrando o domínio de mim.

Se minha memória foi atingida durante certo tempo, ela está de volta melhor do que antes, pois muitas poeiras e escórias que obstruíam meu Ego profundo saíram de minha consciência.

Me chamo Antonin ARTAUD, porque sou o filho de Antoine ARTAUD e de Euphrasie ARTAUD, ainda em vida, enquanto que meu pai faleceu em Marseille em setembro de 1924.

Fui batizado em Marseille no dia 8 de setembro de 1896 na igreja de Chartreux com o nome de Antoine, Marie, Joseph ARTAUD transformado em Antonin ARTAUD, e foi com este nome de Antonin ARTAUD que assinei todos os meus livros:

Correspondência com Jacques Rivière

O umbílico dos Limbos

O Monge

Heliogábalo ou o anarquista coroado

O teatro e seu duplo

Nasci em 14 de setembro de 1896 em Marseille, na Rue du Jardin des Plantes n.4

Quanto ao nome de NALPAS, é como já lhe disse o nome de solteira de minha mãe, que era filha de Louis e de Mariette NALPAS, e que nasceu (minha mãe) em Smyre no dia 13 de dezembro de 1870. Mas não é por este motivo que a mencionei e surpreende-me bastante tê-lo feito." (carta de 20 de julho de 1943, idem, p.52)

É extremamente comovente ver de que maneira ele retoma ao mesmo tempo sua identidade de ARTAUD enquanto inscrita na genealogia de seu pai e sua mãe, e na paternidade de sua obra. 
Porém, alguns elementos delirantes continuam adjacentes, particularmente o elo suposto entre uma das quatro Santas Marias do Mar — Mãe? e o nome de NALPAS — mas a associação com o nome será mantida, apesar de tudo, até o final de sua vida.

Alguns dias depois, em 25 de setembro de 1943, ele mesmo estabelece ligações cuja importância é para nós fundamental: "Há uma coincidência que não posso deixar de lhe assinalar; é que na própria manhã do dia em que o Sr. Delanglade me trouxe esse capítulo de Humpty e Dumpty para que o traduzisse, pensei em recomeçar a escrever, o que não fazia há seis anos." (carta de 20 de julho de 1943, idem, p.64).

Literalmente, ele restabelece um contato com as palavras, cujas convenções parecem ser redefinidas, refixadas, por meio desta tradução:

"Não fui muito além nesta tentativa de explicação verbal. Mas fiquei extremamente chocado quando o senhor mesmo, Sr. Ferdière, mostrou-me que a passagem relativa à invenção verbal pura, e onde conseqüentemente surge mais uma vez o problema sempre pendente das origens da linguagem, era aquela ao qual o Sr. era mais apegado.

- A questão consiste em saber, diz Alice, se o senhor detém o poder de fazer com que as palavras tenham sentidos diferentes.

- A questão consiste em saber quem é o Mestre, diz Humpty, e nada mais." (carta de 20 de julho de 1943, idem, p.65)

Um mês depois, ele percebe nitidamente que deve ficar afastado da questão da realização do ato sexual para não ameaçar o equilíbrio fragilmente reconstruído (carta de 18 de outubro de 1943, idem, p.70), o que vai confirmar em outra carta de 1946 (carta de 10 de março de 1946, idem, p.114).

Por outro lado, ele vai aos poucos retomando contato com o mundo literário: “Escrevi para Jean Paulhan pedindo que me enviasse um exemplar do número de agosto de 1937 da NRF, contendo a Viagem ao país dos Tarahumaras para que eu me recoloque no tom e possa fazer assim a religação" (carta de 11 de dezembro de 1943, idem, p.74).

No início de 1944, recomeça a desenhar: "Estou muito feliz que meus desenhos tenham lhe agradado pois havia mais de vinte anos que não desenhava..." (carta de 5 de fevereiro de 1944, idem, p.78), e dá início a um movimento de historização no que se refere à sua relação com Gaston Ferdière: "o senhor não somente me ajudou a viver, o senhor me convidou a viver quando eu me desgastava" (carta de 5 de fevereiro de 1944, idem, p.79).

Ao mesmo tempo que lhe entregava, ainda naquele dia, o relato de um sonho. 
Os trechos que citamos aqui para sublinhar o quanto a retomada de contato de Artaud com ele mesmo pelo viés da escrita teve como eixo a relação transferencial com Ferdière datam desta mesma época, que vai até o início de 45: “ foi graças ao senhor que recomecei a escrever", diz ele ainda (carta de 9 de março de 1945, idem, p.100).

Tem por projeto escrever um livro sobre o Ego e o infinito, elabora o texto sobre "O surrealismo e o fim da era cristã", e desenvolve, por outro lado, as invenções de linguagem sublinhadas por Micher Demangeat, tentando articulá-las com seus desenhos, que pouco a pouco vão recobrar a forma de retratos feitos com carvão, executados de maneira delicada e sensível (é impressionante observar como os últimos retratos se situam em uma espécie de continuidade reencontrada com os retratos de juventude): ${ }^{29}$ "as frases que anotei sobre o desenho que lhe dei, fui buscá-las sílaba por sílaba em voz alta, trabalhando, para ver se as sonoridades verbais capazes de ajudar na compreensão de meu desenho haviam sido encontradas" (carta de fevereiro de 1946, idem, p.113), e ele vai então se preocupar em fazer novamente valer seus direitos autorais junto aos editores, mantendo para tanto uma correspondência com seu advogado e tomando as atitudes necessárias em relação ao prefeito (cartas de 13 e 26 de março de 1946, idem, p.115-117).

Carta por carta, ${ }^{30}$ os efeitos do trabalho da tradução.

Consideramos que este episódio da tradução de Lewis Carroll foi decisivo na retomada de seu nome por Artaud e, curiosamente, trata-se de um elemento que não reencontramos na escrita dos vários autores que se debruçaram sobre sua obra.

Com exceção de Laurent Danchin, para quem isto parece ser uma evidência. ${ }^{31}$

Formado pela École Normale Supérieure, crítico de arte especializado em arte bruta, Danchin foi, totalmente por acaso, vizinho de Gaston Ferdière no vilarejo escolhido por este para se aposentar. Freqüentaram-se muito, e acabaram se tornando amigos; depois da morte de Ferdière, pareceu natural pedir-se à Laurent Danchin para pôr em ordem os documentos de arquivo, escritos, notas e cartas que este deixara.

Ao examinar tais documentos, Danchin percebeu que o lugar central de todos eles pertencia ou estava ligado a Artaud, e que prestar uma homenagem a um dos dois significava prestar homenagem ao outro - daí sua idéia sobre uma possível publicação. Para tanto, trabalhou com André Roumieux, enfer-

\footnotetext{
29 Ver a este respeito o trabalho primoroso Antonin Artaud, desenhos e retratos, de J. Derrida, P. Thévenin, Gallimard 1986.

${ }^{30}$ Reconhecemos aqui claramente o título da obra de Jean Allouch, "Lettre par Lettre", Erès, 1984.

${ }^{31}$ Conversa particular durante a Jornada Loucura e Criação, Bordeaux, 2003, e op. cit., p.131.
} 
meiro psiquiátrico que fizera carreira em Ville-Évrard e tivera acesso ao dossiê da época sobre Artaud. O resultado dessa cooperação são os dois apaixonantes volumes publicados sob o título Artaud et l'asile [Artaud e o asilo] (DANCHIN \& ROUMIEUX, 1996).

Suas abordagens, mais livres se comparadas aos paradigmas universitários em função das formações acadêmicas diferentes que haviam tido, constituem extraordinária fonte de informações e observações sensíveis e pertinentes. Foram extremamente preciosas para o presente trabalho.

Antes de tudo, devemos introduzir duas precisões: na carta que citamos Artaud se refere a um Sr. Delanglade, que veio lhe entregar o texto de Caroll para que o traduzisse. É preciso acrescentar aqui tratar-se do capelão do hospital de Rodez, que tinha desenvolvido uma relação forte e singular com Artaud. Por esta razão, é com ele que Artaud vai fazer suas primeiras saídas do asilo, e ir até a cidade; e podemos imaginar os tesouros de paciência e delicadeza que isto supunha...

É também muito importante observar que o abade Delanglade era... anglicano e que com este título dava aulas nas escolas das redondezas. Acompanhando Artaud em seus primeiros passos fora do asilo, ele o acompanhou também nos caminhos da tradução.

Enfim, também é importante notar que Euphrasie Nalpas, mãe de Artaud, vinha de uma família de armadores gregos, e que na paisagem de sua infância falava-se grego, francês e inglês.

E o pedido de tradução era trazido por Ferdière, que achava medíocre a que Henri Parisot acabara de publicar e acreditava que Artaud faria melhor.

Aliás, na minha opinião, ele estava certo, pois o texto final produzido por Artaud e publicado com o título "L’arve et l'aume" (1989) ${ }^{32}$ é de excelente estrutura literária e muito pertinente quanto às opções escolhidas na tradução.

É necessário, ainda, falar um pouco a respeito do contexto desta tradução, sobretudo dos dois textos a respeito dos quais já dissemos que haviam sido trocados um pouco antes entre Ferdière e Artaud.

A leitura do Hino aos Demônios, de Ronsard, remete efetivamente a toda uma problemática de filiação, e já aludimos aliás ao alcance dos textos de mestre Eckart; logo, não se trata de dois textos "neutros".

Quanto ao texto de Caroll que deve ser traduzido, ele certamente também nada tem de neutro.

Trata-se em primeiro lugar do Jabberwocky, aquele misterioso poema escrito sobre um espelho (ou seja, ao avesso) que encontramos logo no início do segundo tomo das aventuras de Alice.

\footnotetext{
${ }^{32}$ Duas palavras que não existem, mas com as quais é possível fazer jogos de palavras, como 'larva' e 'o homem'. [N. da T.]
} 
Misterioso, porque é preciso um espelho para lê-lo; misterioso por seu sentido, que parece codificado ou esotérico, ou... sem sentido.

No texto de Caroll, é no diálogo com Humpty Dumpty, o mestre das palavras, que o significado das palavras obscuras do poema vai, aos poucos, ser dado.

Aquele diálogo que começa por a pergunta“What's your name and your business?” feita à Alice. Pergunta esta que remete a um contexto dos mais ardentes na problemática do tradutor Artaud.

Pareceu-nos interessante propor um pequeno exercício a uma amiga inglesa próxima, situada fora do campo relacionado à psicanálise, não especializada nem em Caroll e nem em Artaud.

Ela havia lido as aventuras de Alice durante a infância, mas não tinha nenhuma lembrança de ter se apegado a ler esse poema, pelo menos por inteiro.

Pedi-lhe que o lesse e que, sem pensar demais, elaborasse um texto em francês (ela mora na França há 50 anos) dando-lhe um sentido, mesmo aproximado, se ao menos ela pensasse que havia algum sentido ali.

Eis o resultado:

JABBERWOCKY (tradução livre de Elizabeth Lucas)

Desconfie do Jabberwocky, meu filho

Os dentes que mordem, as garras que aprisionam

Desconfie de Jujub e evite-o.

Ele pegou sua espada na mão

Durante muito tempo procurou o inimigo

Deitou-se ao lado da árvore em T, e refletiu...

E enquanto refletia, o Jabberwocky com olhos de chamas

Chegou barulhento pelos bosques cantarolando

1-2, 1-2 de lado a lado a lâmina fez seu trabalho

e deixou-o morto com sua cabeça, indo logo para casa

E você matou o Jabberwocky, em meus braços, filho

Oh! dias felizes.

Ele exultou de alegria.

Continuando minhas pesquisas sobre Carroll e a escrita de Alice, eu então descobri que, na adolescência, o autor havia organizado uma espécie de glossário, junto com seu irmão, feito de palavras provenientes mais do inglês mais ou menos antigo, do que de invenções puras, um glossário retomado em boa parte no diálogo com Humpty Dumpty.

Ágora (Rio de Janeiro) v. X n. 1 jan/jun 2007 9-34 
Consegui achá-lo, fiz com que chegasse até minha amiga, e lhe perguntei se com este suporte, ela estaria de acordo em rever sua cópia.

Eis o resultado:

JABBERWOCKY (segunda tradução E.L., levando em consideração o glossário de Lewis Carroll)

Era de tarde e os texugos ativos

Cavavam buracos no talude.

Bem infelizes estavam os papagaios

E as tartarugas graves gritavam

Desconfie do Jabberwocky, meu filho

Os dentes que mordem, as garras que ferem

Desconfie do pássaro Jujub e evite

O furioso kidnapper de bandos

Pegou em sua mão sua espada mágica

Durante muito tempo o inimigo horrível procurou

Descansando perto da árvore de tambom

Como pensava com cólera

O Jabberwocky com olhos de chamas

Chegou soprando através dos bosques

Sussurrando sobre o caminho

1-2, 1-2 e de lado a lado

a espada mágica fez flic-flac

ele o deixou morto, e com sua cabeça foi a galope para casa

Eh, você matou o Jabberwocky?

Para os meus braços, meu filho radiante

Oh! dia feliz. Hourrah, hourrah.

Ele cacarejou de alegria.

Se meus agradecimentos afetuosos vão para a amiga que aceitou a função de traduzir, não se trata de discutir aqui o ‘acerto’ de sua tradução no plano literário. O que era de meu interesse, em relação às minhas hipóteses relativas a Artaud e ao fato de ter visto que o inglês pertencia ao campo das línguas faladas em torno dele durante sua infância, era saber se este texto, que para aqueles cujo inglês não é a língua materna, se apresentava como sem sentido, tinha o mesmo efeito para alguém para quem o inglês fornecera a matéria de sua "lalangue". 
Fiquei muito interessado em ver, primeiro, que a leitura original tinha desorientado um pouco a leitora, mas que uma estrutura (a mínima) de sentido tinha aparecido de imediato, e que, grosso modo, a estrutura de sentido percebida na primeira leitura fora confirmada pelo uso do glossário de Carroll.

Aliás, tudo leva a crer que esta questão do sentido fora perceptível a Artaud, que dá como subtítulo a seu texto L’arve et L'aume: “tentativa antigramatical a propósito de Lewis Carroll” — não se faz algo antigramatical sem antes se perceber uma gramática...

Fiquei também muito interessado em uma observação complementar, feita em volta de uma xícara de chá quando falávamos outra vez a respeito deste texto: "mas você sabe, to jabber quer dizer 'falar'."

Ocorreu-me que a tradução podia aplicar-se também ao nome que é o título do poema, a saber, o "jabberwocky” mesmo, e que podíamos arriscar, para este exercício, "o Parlotteux".

Ainda que seja encontrado em traduções, o nome próprio não se traduz. Neste caso, a relação de assonância entre Jabberwocky e jabber deve ser posta em evidência, mesmo pagando o preço da transgressão de uma regra de ouro.

Pouco importa se o achado deve ou não ser guardado por si, mas me parece que o essencial é a idéia que ele sublinha: a saber, que a relação com a palavra é central neste texto, e isto inclusive até no nome, tanto do personagem quanto do título.

Aparece também, se fizermos outra leitura do texto substituindo "Jabberwocky" por "Parlotteux", que o texto termina sobre o assassinato do "Parlotteux".

Fica difícil então não nos perguntarmos em que esta morte do impostor da palavra, que seria o "Parlotteux", pode contribuir para uma operação permitindo que se ponha novamente em jogo um dos operadores lógicos do assassinato da Coisa, assassinato original da aparição da própria linguagem para todo sujeito humano, a saber: aquilo que de uma das funções dos Nomes do Pai encontra-se suportado pelo patronímico.

Na introdução de sua obra, Jean Allouch indica que, no que diz respeito à relação do significante e da letra, trata-se de mostrar "como a letra vem se encarregar do significante, até a 'desjuntá-lo’ de seu referente” (ALLOUCH, 1984, p.22).

No contexto de Artaud, como no de Wolfson e de outros, mas singularmente, é claro, concordamos com o que Guiraud propunha como definição da passagem da relação à palavra na psicose: “avisamo-lo(la) por sinais, ele(a) transmite seu pensamento por uma espécie de telégrafo sem fio e recebe a resposta sob forma de intuição" 33

\footnotetext{
${ }^{33}$ P. Guiraud, "as formas verbais da interpretação delirante”, Annales Médico-psychologiques, Paris, Premier semestre 1921, p.405, citado por Allouch, op. cit., p.203.
} 
Logo, qualquer intervenção sobre a letra é suscetível de adquirir uma importância particular e de ter um efeito sensível.

Singularmente, neste registro de funcionamento, as distinções que Allouch introduz de início em seu trabalho devem ser reavaliadas: "Escrever nomeia-se transcrever, quando o escrito é regulado sobre o sentido, e transliterar quando se regula sobre a letra" (ALLOUCH, 1984, p.18).

Uma operação iniciada em um registro, no presente caso, traduzir, pode ter de passagem um efeito de ativação de alguma outra, a qual se refere à letra, e por sua vez terá efeitos sobre a escrita que será feita a partir desta tradução.

No que se refere a essa tradução feita por Artaud, é de fato essencial que, se desejarmos medir-lhe o impacto, sublinhemos que, uma vez estabelecida, ela é publicada e retorna, assim, ao sujeito que a comete, restabelecendo-o enquanto autor.

"A transliteração intervêm na leitura, ligando o escrito ao escrito: ela dá assim seu alcance àquilo que geralmente é admitido como secundário ao escrito (...) Esta 'secundariedade' do escrito em relação à palavra não passa da recaída dessa secundariedade fundamental do escrito em relação a ele próprio. O escrito é o que resulta de sua definição pela transliteração, sempre esteve ligada ao que Queneau já inventara ao criar o nome de segundo grau" (idem, p.17) sublinha Allouch, antes de afirmar que "sobre o que liga o escrito a certo modo de presença do outro" (idem), não é possível deixar de consultar a experiência psicótica.

Acompanhando os escritos de Artaud, vimos como esta função do "segundo grau" era insuportável enquanto tal e quase precisava ser reinventada; aqui, dentro e através do trabalho de tradução, trata-se de pegar as palavras em sentido contrário situando-se no nível da letra, o que no contexto particular das transferências que aí estão tem um efeito de ativação de uma função fundamental de ancoragem que estava "enguiçada", e supre por uma solução de "substituição" tirada também da bateria de significantes fornecidos pela história pessoal que havia levado a substituir um patronímico — aquele do pai — por outro, aquele da mãe.

Na busca perpétua de uma superfície de inscrição, de algo que permita ligar o corpo, a história e o ser, assim surge Artaud, ocupado com a escrita, como ele mesmo se situa, assim como Michel Demangeat observa ao terminar seu artigo, "entre o desmoronamento central da alma" e o fato de reconquistar, recriar mais e mais a superfície do quadro... a superfície da página”. ${ }^{44}$

Há, entretanto, um restabelecimento da função do patronímico, um tempo inativo e "gelado" que vai mostrar-se durável e definitivo.

\footnotetext{
${ }^{34}$ Michel Demangeat, artigo no prelo, p.16.
} 
Ainda que deixe o sujeito Antonin Artaud à beira do precipício; pelo menos é em seu próprio nome que ele introduz, em Ci-Gît [Aqui jaz], esta questão vertiginosa:

“Eu, Antonin ARTAUD, sou meu filho,

meu pai,

minha mãe,

e eu.?"

para sempre suspensa em sua tentativa, antagonista àquela de Joyce, de se "reinscrever" no inconsciente e no universo da língua, destinado a ser "aquele velho Artaud, nome etimológico do nada”.

Recebido em 9/12/2005. Aprovado em 7/1/2006.

\section{REFERÊNCIAS}

ALLOUCH, J. (1984) Lettre par Lettre. Paris: Erès. ARTAUD, A. Oeuvres Complètes. Paris: Gallimard. (1964) Le théâtre et son double. Coll. Folio-Essais, n. 14. (1964) "Sur le théâtre balinais", in Le théâtre et son double, coll. Folio-Essais, n. 14. Paris: Gallimard.

(1964) “Un athlétisme affectif”, in Le théâtre et son double, coll. Folio-Essais, n. 14. Paris: Gallimard. (1936/1964) “Théâtre de Séraphin”, in Le théâtre et son double, coll. Folio-Essais, n. 14. Paris: Gallimard.

(1977) Nouveaux Écrits de Rodez. Paris: Gallimard.

(1989) L'arve et l'aume. L’Arbalette.

DANCHIN, L. \& ROUMIEUX, A. (1996) Artaud et l'Asile. Ségnier.

DEMANGEAT, M. (1995) La scène, le sacré, la survie. Actes du colloque Psypropos 1994: Du cri à l'écrit. Orléans, p.113-125.

"Mort et Transfiguration: origines du nouveau style d'Artaud à partir des lettres de Rodez” (in Eidolon). No prelo.

DEMANGEAT, M. \& EFEL, F. (2002) Colóquio sobre as psicoses (realizado em Bruxelas). No prelo.

DERRIDA, J. (1967) “La parole soufflée”, in L'écriture et la Différence. Paris: Seuil. 
(1967) "Le théâtre de la cruauté et la clôture de la représentation”, in L'écriture et la Différence. Paris: Seuil.

(2003) Artaud le Moma. Paris: Alliance Française.

\& THÉVENIN, P. (1986) Antonin Artaud, dessins et portraits. Paris:

Gallimard.

Serge Bedere

serge.bedere@wanadoo.fr

Ágora (Rio de Janeiro) v. X n. 1 jan/jun 2007 9-34 